\title{
Portfolio : Facettes de la cristallographie
}

\section{(2) OpenEdition \\ 1 Journals}

Édition électronique

URL : https://journals.openedition.org/rbnu/1702

DOI : 10.4000/rbnu. 1702

ISSN : 2679-6104

\section{Éditeur}

Bibliothèque nationale et universitaire de Strasbourg

\section{Édition imprimée}

Date de publication : 1 novembre 2014

Pagination : 92-101

ISBN : 9782859230548

ISSN : 2109-2761

Référence électronique

"Portfolio : Facettes de la cristallographie », La Revue de la BNU [En ligne], 10 | 2014, mis en ligne le 01 novembre 2014, consulté le 26 mai 2021. URL : http://journals.openedition.org/rbnu/1702 ; DOI :

https://doi.org/10.4000/rbnu.1702

\section{(c) (i) (2)(2)}

La Revue de la BNU est mise à disposition selon les termes de la Licence Creative Commons Attribution - Pas d'Utilisation Commerciale - Partage dans les Mêmes Conditions 4.0 International. 


\section{Facettes de la cristallographie}

Les Nations Unies ont décrété l'année 2014 année internationale de la cristallographie. A cette occasion, le Jardin des sciences de l'Université de Strasbourg a proposé un certain nombre d'actions, en direction du grand public comme des publics scolaire et universitaire. Parmi les manifestations, l'exposition Les 1001 facettes de la cristallographie a mis en lumière cette discipline, racontant son histoire et présentant les recherches contemporaines. Les images qui suivent sont extraites de cette exposition. Depuis les modèles pédagogiques jusqu'au diffractomètre de laboratoire, elles rendent compte de la façon dont les scientifiques donnent à voir l'infiniment petit. 
TYPE 1.

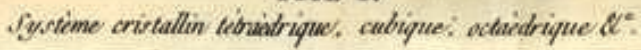

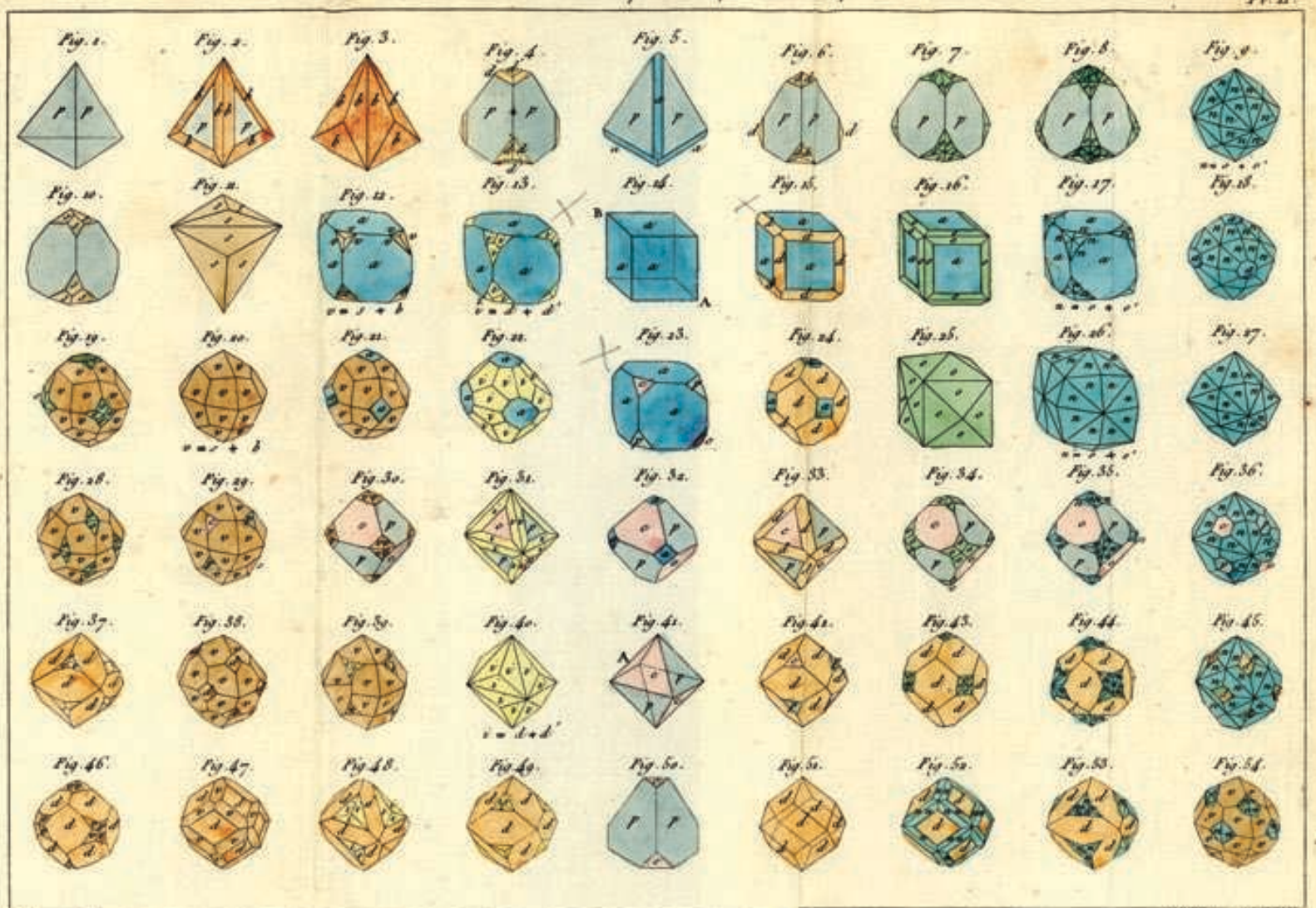

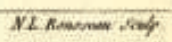




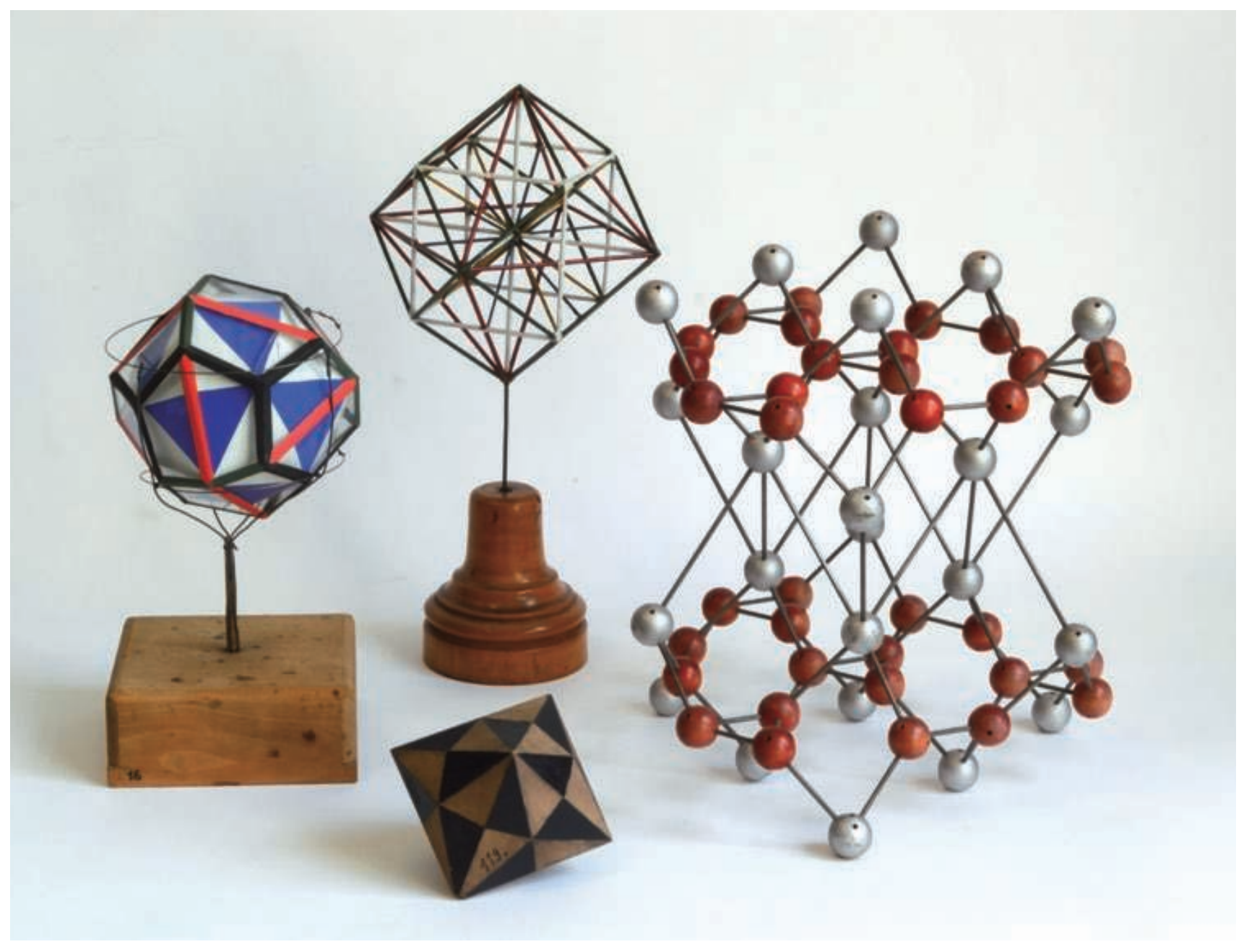




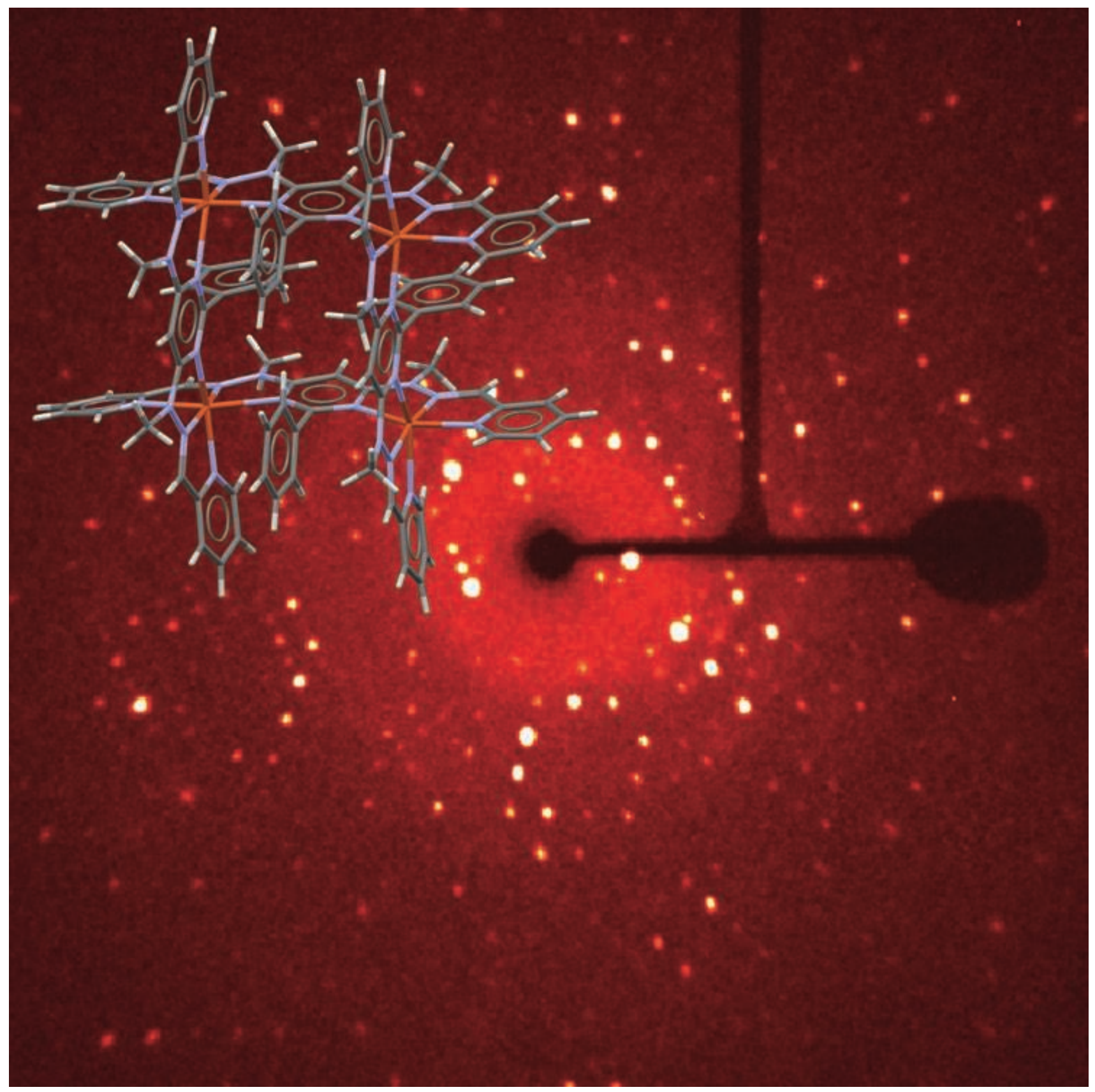

Structure cristallographique d'une grille moléculaire de cuivre et cliché de diffraction associé (coll. Université de Strasbourg) 


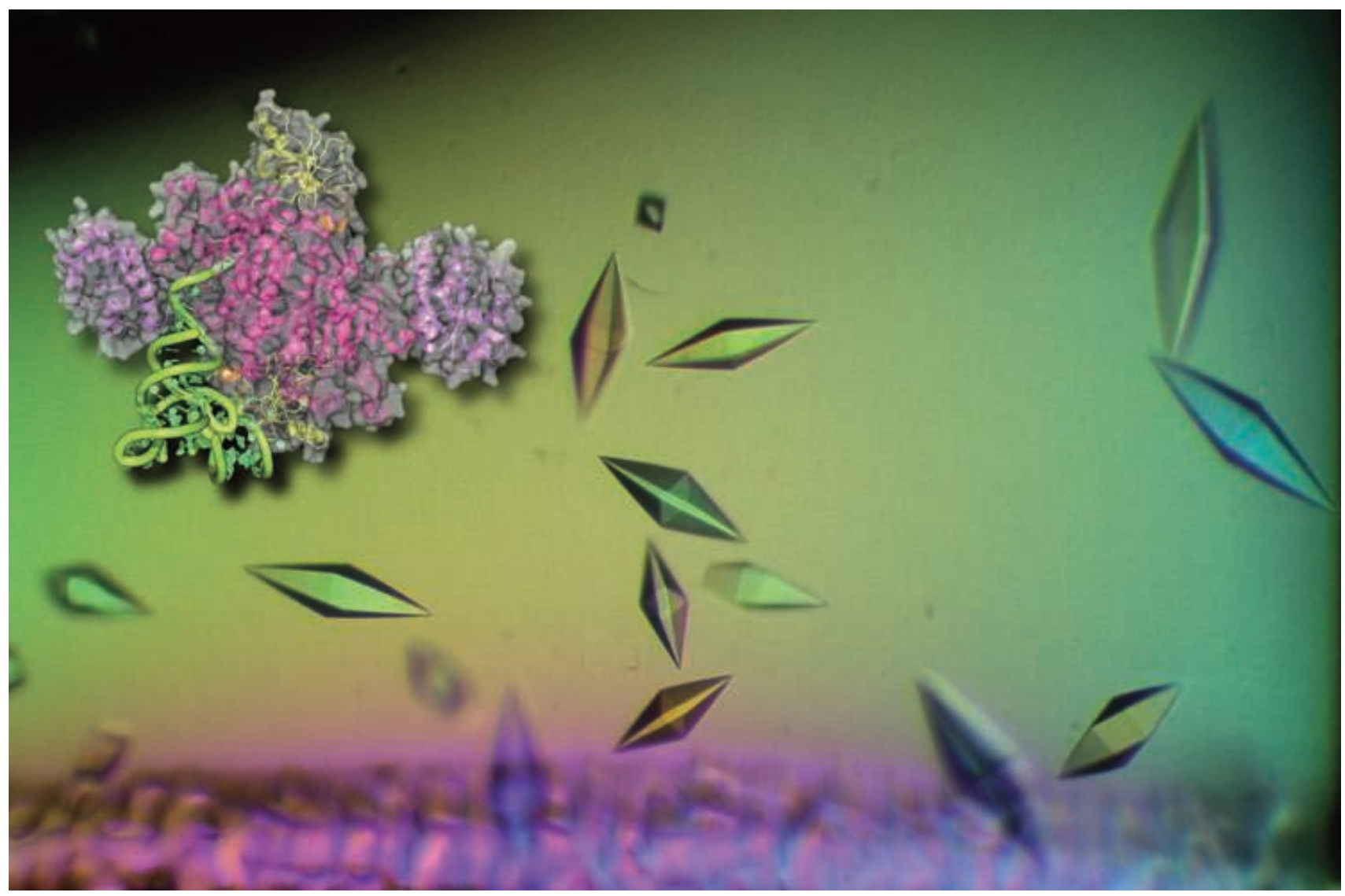




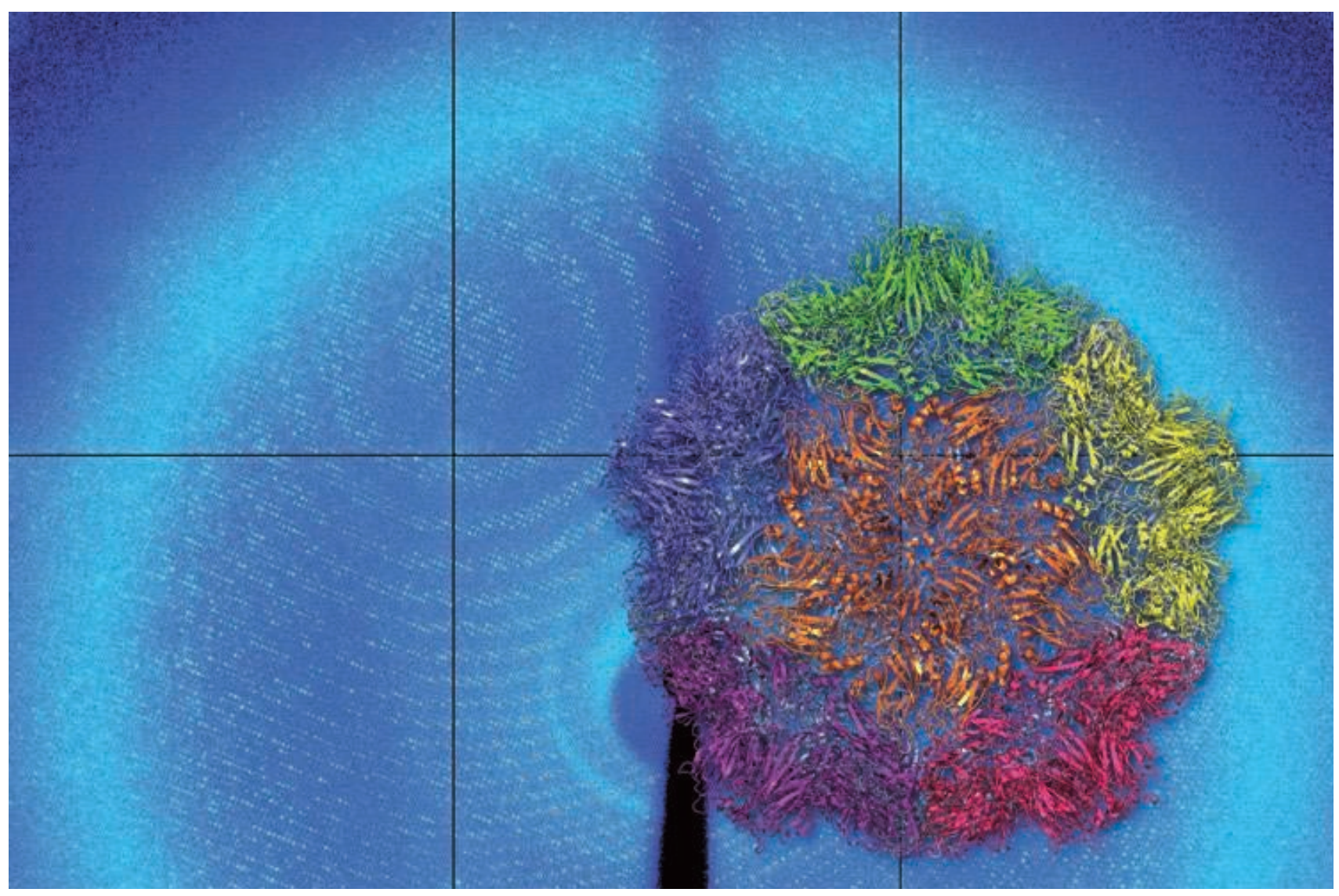

Image de diffraction et architecture 3D du virus du court-noué de la vigne (coll. Université de Strasbourg) 


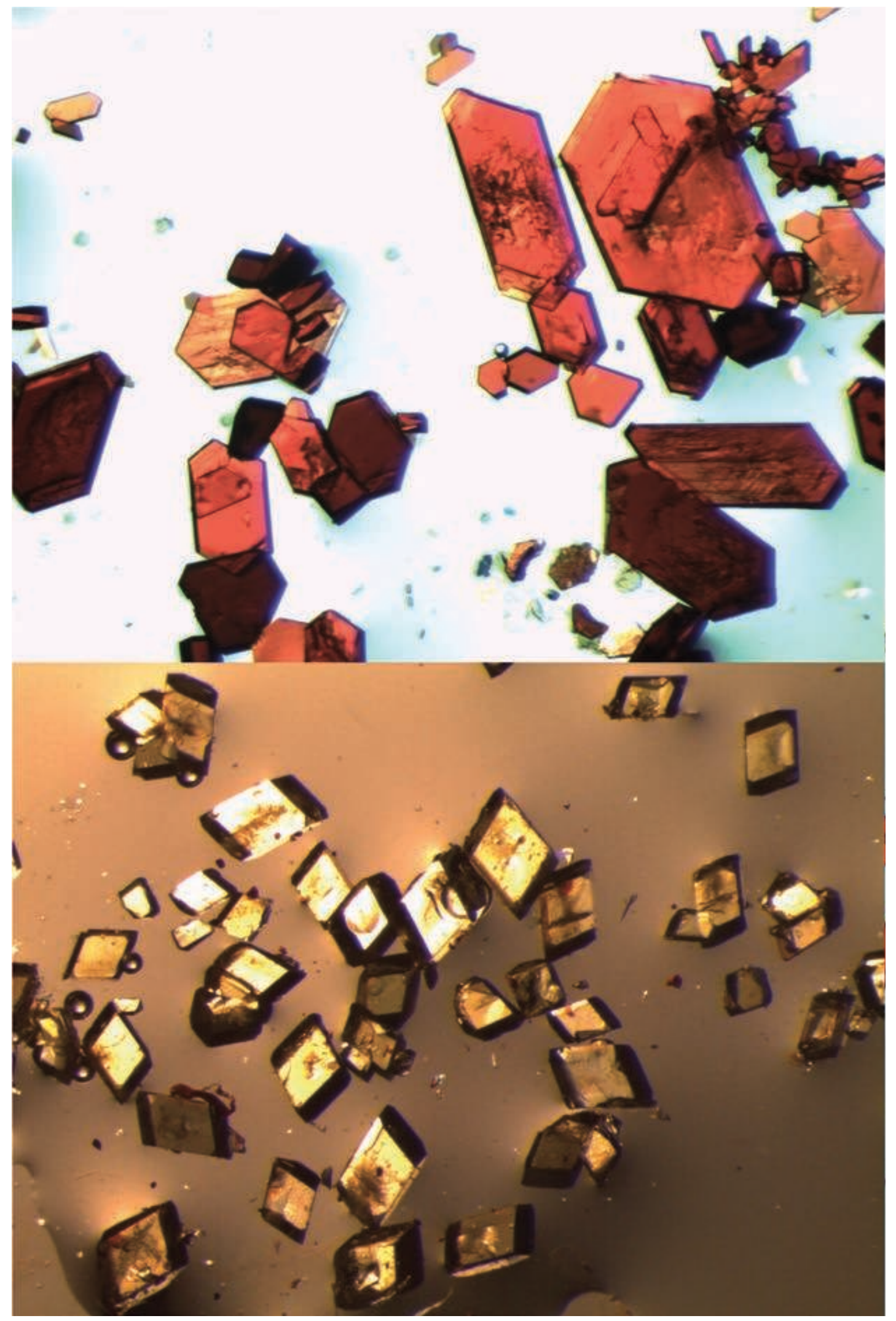




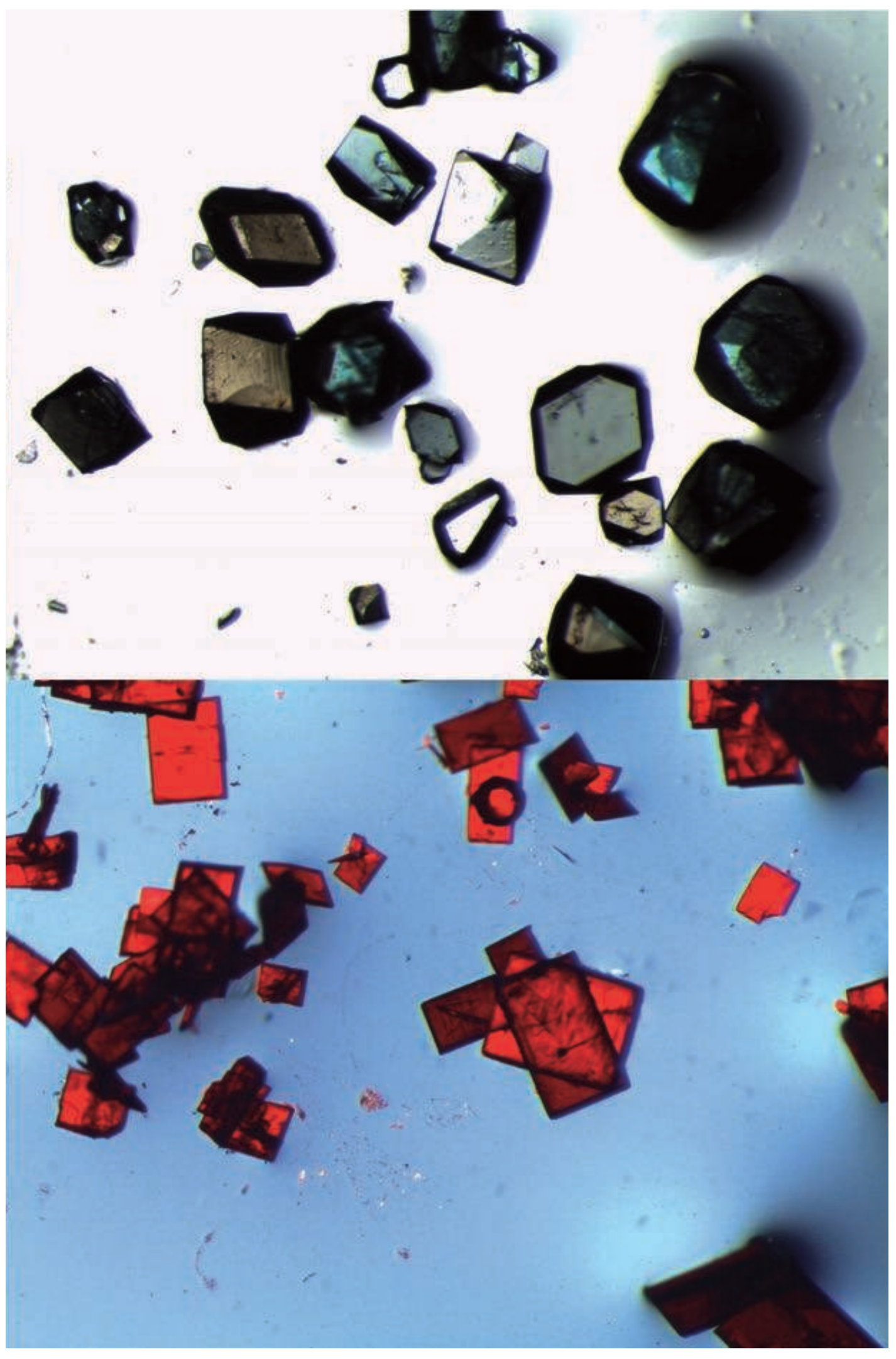

Micro-cristaux de différents composés chimiques aux formes et couleurs variées (coll. Université de Strasbourg) 


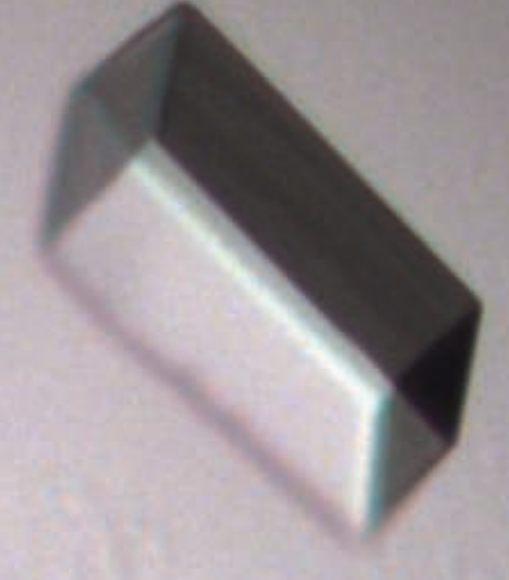

한
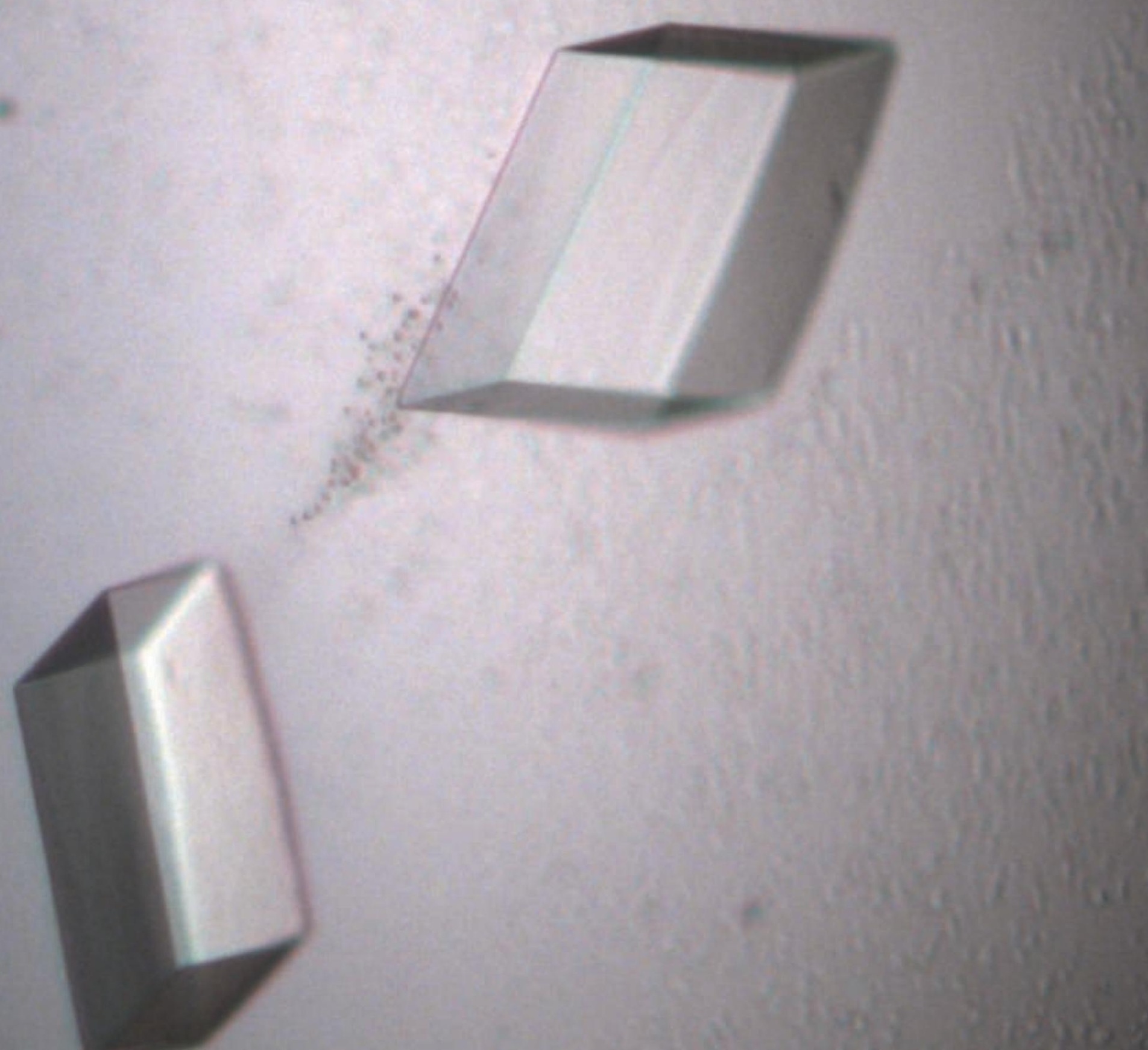


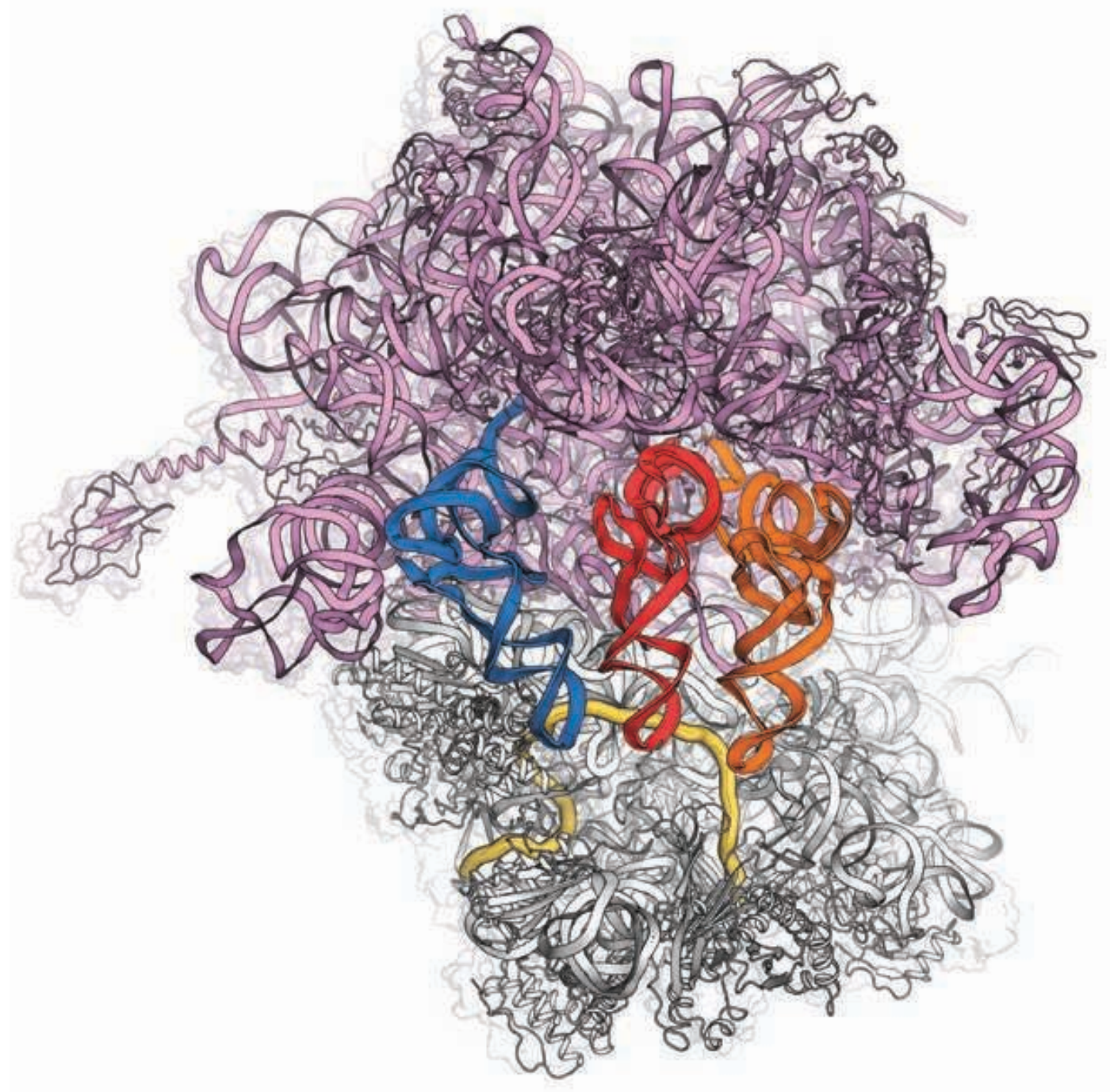

Cristaux et représentation $3 \mathrm{D}$ détaillée du ribosome,

l'usine à protéines de la cellule (coll. Université de Strasbourg) 